\title{
As lanchas "ajato" no Solimões: modernização pretérita e integração territorial
}

\section{The "ajato" boats on the Solimões river: preterite modernization and territorial integration}

Kristian Oliveira de Queiroz- Doutor em Geografia Humana pela Universidade de São Paulo (USP). Professor da Universidade do Estado do Amazonas (UEA). E-mail: kssqueiroz@ gmail.com

\section{Resumo}

Este artigo visa analisar o papel das lanchas "ajato" para a modernização do transporte fluvial no Solimões e para a integração territorial deste subespaço a partir de uma proposta de classificação baseada na origem dos fluxos destes barcos rápidos. Evidencia-se que as lanchas "ajato" são objetos submetidos a um processo de "modernização pretérita" em que o uso de técnicas e equipamentos antigos provenientes de divisões territoriais do trabalho pretéritas ainda é útil para a circulação fluvial na região. Mediante o levantamento bibliográfico e documental e o trabalho de campo, verificou-se que estas embarcações contribuíram para a modernização dos fixos especializados na navegação via a inserção de infraestruturas diferenciadas como o Terminal do "Ajato" de Tefé; bem como viabilizaram a modernização dos fluxos com o uso da rapidez e da organização dos serviços, promovendo integração e fluidez territorial significativas neste subespaço amazônida.

\section{Palavras-chave}

Modernização pretérita. Integração territorial. Transporte fluvial. Rio Solimões. Amazonas.

\begin{abstract}
This article aims to analyze the role of "ajato" boats for the modernization of river transport in the Solimões and for territorial integration of this subspace via a classification proposal based on the origin of the flows of these fast boats. This researche shows that the "ajato" boats are objects subjected to a process of «preterite modernization», where the use of old techniques and equipment from old territorial divisions of labor is still useful for river circulation in the region. From bibliographical and documentary research and field work, it was verified that these boats contributed to the modernization of the specialized infrastructures in the navigation through the insertion of the Terminal of the "Ajato" of Tefé; as well as made possible the modernization of the flows with the use of the speed and the organization of the services, promoting significant integration and fluidity territorial in this amazonian subspace.
\end{abstract}

\section{Keywords}

Preterite Modernization. Territorial integration. River transport. Solimões River. Amazonas. 


\section{INTRODUÇÃO}

O transporte fluvial no rio Solimões no estado do Amazonas possui desafios infraestruturais, institucionais e administrativos que se reproduzem em toda a região amazônica. No entanto, a busca pela intensificação dos fluxos e dos lucros nesta região levou o desenvolvimento de um segmento da circulação fluvial que oferece a aceleração e a velocidade como vantagens que os lentos e tradicionais barcos do rio Solimões não proporcionam, promovendo a diminuição da duração das viagens intermunicipais na região.

As Lanchas “ajato" também conhecidas como "expressos”, já fazem parte da paisagem do transporte fluvial no Amazonas (Figura 1). Estas embarcações velozes e potentes representam o produto de uma modernização aquaviária, configurando o que Harvey (2005, p.47) chama de "anulação do espaço pelo tempo".

Figura 1 - As lanchas "ajato" também conhecidas como "expressos"

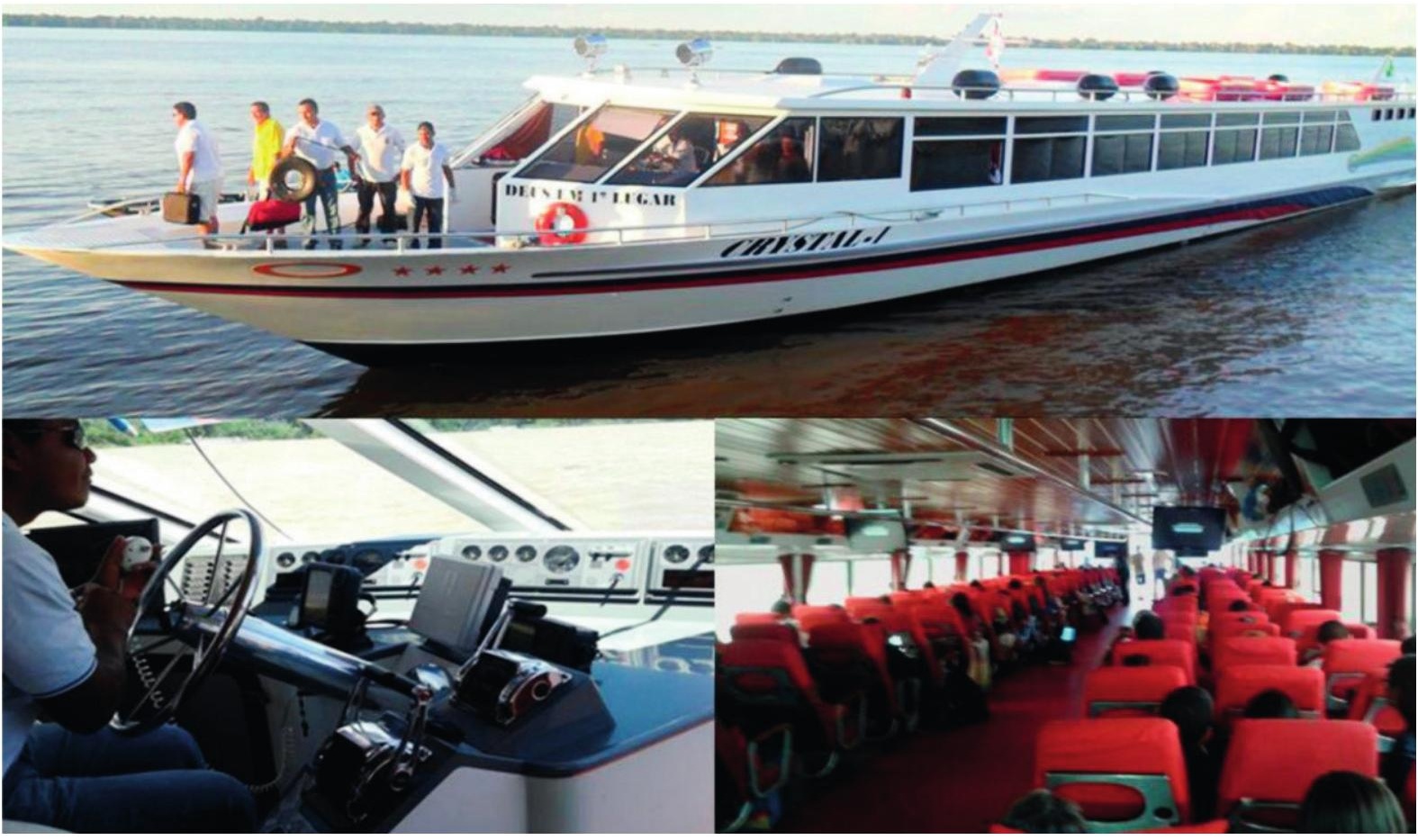

Fonte: Acervo do autor, 2016

Este segmento da circulação de passageiros no rio Solimões, acaba por contemplar a combinação das necessidades do cotidiano regional e a expansão de 
novas técnicas advindas da divisão territorial do trabalho provenientes de espaços luminosos. Isto promove uma dialética do território, o confronto dialogado entre o velho e novo, o local e o global, as verticalidades e as horizontalidades (SILVEIRA, 1999, p. 400).

O objetivo deste artigo é realizar uma leitura do papel dos fluxos das lanchas "ajato" na modernização do transporte fluvial assim como compreender a sua contribuição para a integração territorial deste subespaço ao meio geográfico contemporâneo (Figura 2).

A hipótese de que a atuação dessas lanchas proporcionou uma modernização seletiva no percurso hidroviário do rio Solimões amazonense ocasionando impactos referentes à dinâmica e à circulação econômica e social orientou esta pesquisa. O levantamento bibliográfico e documental e o trabalho de campo realizado em toda a extensão do rio Solimões foram a base metodológica do estudo.

Figura 2 - Área de estudo - o Rio Solimões

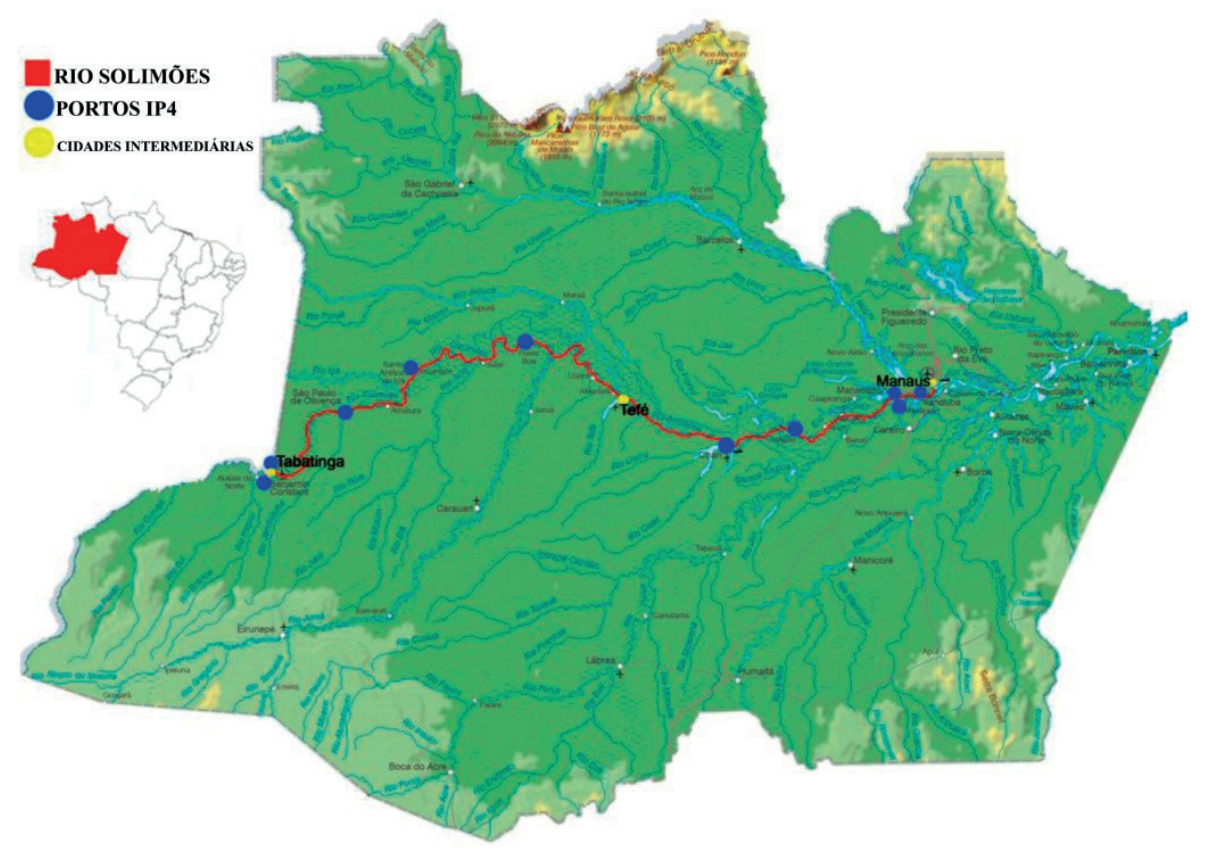

Fonte: Elaboração própria com base de dados do IBGE/2013 
Este trabalho oferece subsídios para compreender que as lanchas "ajato" são objetos submetidos a um processo de "modernização pretérita", em que o uso de técnicas e equipamentos antigos advindos de divisões territoriais do trabalho pretéritas ainda é útil para disseminar mobilidade e rapidez.

Para uma melhor leitura de uma modernização pretérita a partir do transporte fluvial no Solimões, elaborou-se uma proposta de classificação a partir da origem dos fluxos de tais lanchas. Considera-se que as técnicas e infraestruturas a elas relacionadas, bem como os fixos especializados à navegação, modificamse quanto mais se afastam do ponto primordial de irradiação dos fluxos. Desta forma, classificou-se como fluxos primários aqueles constituídos pelas lanchas que partem de espaços luminosos, que, no Amazonas, são advindos da sua capital Manaus, onde os elementos do meio técnico-científico-informacional, o meio geográfico contemporâneo (SANTOS, 2008), são mais densos e atuantes na dinâmica do espaço.

Os fluxos secundários partem das cidades intermediárias do rio Solimões para outros municípios no interior do estado. Admite-se que as hinterlândias de Tefé e Tabatinga corroboram para uma produtividade espacial vinculada a esses fluxos secundários significativos. Isto se justifica por Tefé ser o maior centro urbano e possuir a maior região de influência no estado do Amazonas após a capital Manaus; e por Tabatinga possuir alta frequência de fluxos em razão de estar exposta à porosidade territorial (ARRROYO, 2015) da tríplice fronteira onde os territórios do Peru, Colômbia e Brasil se encontram.

$\mathrm{E}$, finalmente, os fluxos terciários, que representam aqueles irradiados das cidades intermediárias ou regionais para as centenas de comunidades ribeirinhas localizadas nos afluentes, subafluentes, furos, paranás e igarapés da Bacia do rio Solimões. Esses fluxos terciários são movidos pelos serviços oferecidos por lanchas menores via fretamentos por firmas, instituições e pessoas para fins diversos.

Ressalta-se que as lanchas de cada fluxo categorizado possuem diferenças relevantes relacionadas à estrutura, equipamentos e técnicas de operacionalização. Por conseguinte, rotas distintas e diferentes tipos de lanchas estabelecem uma rede ligando a determinados nodais de embarque e desembarque de passageiros no rio Solimões. 


\section{1 “DUELO DE OBJETOS” E MODERNIZAÇÃO PRETÉRITA NO SOLIMÕES}

As embarcações de transporte fluvial de passageiros da empresa "Ajato", pertencentes ao segmento Lancha-Motor (L/M) no Amazonas, oferecem serviços distintos que aprimoram a qualidade das viagens realizadas no Solimões quando comparados com seus concorrentes representados pelos barcos tradicionais conhecidos como Recreios, do segmento Navio-motor (N/M) e as embarcações do segmento ferry-boat (F/B).

Reflete-se sobre a coexistência de embarcações diferentes na mesma rota no Solimões; representantes de divisões do trabalho de diferentes temporalidades onde circulam as lanchas rápidas e com tamanhos medianos navegando juntamente com os grandes, lentos e tradicionais Navios-motores ou Recreios.

As diferenças organizacionais são significantes entre eles. Os recreios se caracterizam pelo transporte fluvial misto, no qual passageiros viajam em redes, misturados às bagagens no convés ou nos poucos camarotes disponibilizados. Nesses barcos tradicionais, os passageiros fazem filas para as refeições e para o uso dos banheiros. As cargas excedentes do porão (eletrodomésticos, móveis, alimentícios, vestuários, eletrônicos, motocicletas, material de construção, etc.) são alocadas entre aos passageiros.

Nas lanchas “ajato”, o serviço se assemelha ao do transporte aéreo, onde a tripulação leva as refeições aos assentos dos passageiros, as respectivas bagagens são separadas dos clientes e a rapidez e pontualidade nos embarques ou saídas das cidades se configuram como grande diferencial (Quadro 1).

Quadro 1-O "Duelo dos Objetos"

\begin{tabular}{|l|l|}
\hline \multicolumn{1}{|c|}{ LANCHA “AJATO” } & \multicolumn{1}{c|}{ NAVIO-MOTOR } \\
\hline 1- Bagagens Separadas & 1- Transporte misto \\
2- Poltronas & 2- Redes e camarotes \\
3- Refeições personalizadas & 3- Refeições organizadas por filas \\
4- Rapidez e Pontualidade & 4- Lentos e suscetíveis a atrasos \\
5- Equipamentos modernos de navegação & 5- Equipamentos tradicionais de \\
6- Receitas: passagens com valor único e & navegação \\
fretes por quilo. & 6- Receitas: passagens com preço variável \\
& e fretes por volume. \\
\hline
\end{tabular}

Fonte: Elaboração própria, 2017 
A diferença na duração das viagens exibe outra característica das lanchas “ajato", pois enquanto a duração da viagem de Manaus para Tefé é de 12 horas, um Navio-Motor leva até 36 horas para realizar o mesmo trecho. O preço das passagens também se distingue. A passagem com acomodação em rede no naviomotor é mais popular (entre 30 a 60 reais no trajeto exemplificado), os camarotes destas embarcações são mais caros (em torno de 550 reais no respectivo trajeto). O preço da passagem ou poltrona de uma lancha "ajato" é maior que a passagem de rede em um Recreio, porém é menor que o camarote deste (220 reais), em concorrência direta com o preço do transporte aéreo, se esta passagem de avião for comprada com planejamento prévio (em torno de 240 reais ou até mais barata). Aqueles viajantes com relativo poder aquisitivo, ou que estão em situações de urgência ou que não gostam das alturas dos aviões, viajam de "ajato".

Refletindo sobre o comportamento dos clientes que não utilizam o transporte aéreo para suas viagens, pois preferem o transporte fluvial, observase o que Baudrillard (2012, p. 89) chama de "duelo de objetos" ou "duelo de consciências". Neste sentido, o transporte fluvial composto de navios-motores e lanchas "ajato" mostra respectivamente o "tradicional-funcional-antigo" e o "moderno-funcional-antigo". As lanchas se misturam ao conjunto de funcionalidades e significações construídas pelos passageiros/clientes em relação aos antigos navios-motores. Ambos efetuam as mesmas funções admitindo significados diferentes, uma modernização do antigo utilizando procedimentos pretéritos para produzir significados novos.

Admite-se que uma modernização se concretiza e se difunde no espaço por intermédio de suas funcionalidades e de seus significados provenientes da inserção de inovações técnicas e estruturas que lhe permitam evoluir e se desenvolver em função do aprimoramento de objetos, ações e do modo de produção.

Desta forma, uma "modernização pretérita" se configura quando objetos caducos e pretéritos são utilizados na ausência de condições materiais e imateriais que propiciem a operacionalidade de objetos sofisticados e modernos. Por conseguinte, ocorre o funcionamento de um sistema técnico vinculado a uma configuração territorial apta a servir estes objetos, porém um sistema técnico pretérito em uma configuração territorial limitada.

Refere-se à adaptação da construção das lanchas, utilizando materiais de qualidade secundária e adaptados à estrutura dos barcos, como por exemplo, no 
acabamento interno e no sistema de ar-condicionado. Se estes barcos fossem construídos com material sofisticado e técnicas contemporâneas, sua manutenção e funcionamento seriam pouco eficientes em subespaços como o Solimões, onde a assistência técnica para objetos sofisticados é rarefeita. A especialização do lugar providencia a especialização dos fluxos, logo, a modernização dos lugares pode se realizar concomitantemente com a modernização destes fluxos. Concorda-se com Huertas (2007, p. 251) quando afirma que as consequências das inovações tecnológicas mais influentes na navegação regional amazônida são, respectivamente: o aumento da velocidade, com a gradativa troca de embarcações de madeira por embarcações de ferro ou aço, assim como a inserção e uso de motores mais potentes que propicia o aumento da capacidade de carga e a redução do custo de produção.

As lanchas são feitas por encomenda, com procedimento de construção quase artesanal. O design é chamado de modelo "manauara" pelo Sr. Aguiar, que é o idealizador e proprietário da empresa "Ajato Navegações Ltda-ME", tão notória que o segmento leva seu nome em função da força do uso, ou seja, "lanchas ajato".

Entretanto, não há uma padronização das estruturas internas, isto produz diferenças entre as lanchas que evidenciam o uso de técnicas não tão modernas nestes barcos alternativos. Por exemplo, a Lancha Crystal I, a maior lancha "ajato" no Amazonas que realiza a rota no Solimões, possui um sistema de ar condicionado moderno, embutido e discreto. No entanto, outras lanchas que também operam no rio Solimões, baseadas na cidade de Tefé, por exemplo, possuem esse sistema de ar condicionado com aparelhos antigos e adaptados à estrutura interna da lancha, muitas vezes, viajam gotejando água nos passageiros. Porém, são embarcações aptas a funcionarem em lugares onde existe o acesso à manutenção destes equipamentos mais simples, o que não ocorreria se fossem embutidos e sofisticados como da Crystal I, que também opera em todo rio Solimões, mas voltam a Manaus para reparos e manutenção. Aspectos de uma modernização com uso de equipamentos pretéritos, e que se intensifica quanto mais longe dos centros que sediam objetos e técnicas contemporâneas.

Inserem-se neste contexto de uma modernização pretérita a baixa estruturação dos fixos especializados, produto da relativa presença e eficiência das políticas do Estado no rio Solimões, ocasionando problemas como a inexistência de portos organizados, a baixa fiscalização e pouco policiamento. 
Ressalta-se que, dentre os fixos especializados à navegação que promovem um papel crucial ao suporte logístico no Solimões, destacam-se os "Pontões", como são chamados os postos de combustíveis flutuantes que também oferecem serviços de mercearia ou mercados fluviais, e que são muito presentes nos municípios de Tefé, Coari e Tabatinga. No entanto, em muitas cidades que não possuem Pontões há flutuantes e barcos de madeira de propriedade de comerciantes que realizam a venda de combustíveis às embarcações em geral que buscam abastecimento. Representam a limitação das infraestruturas que configuram os fixos especializados no Solimões, pois lanchas "ajato", que consomem em média 200 litros de combustível por hora e prezam pela rapidez, também pedem velocidade no abastecimento. Todavia, flutuantes antigos e precários de madeira, que efetuam o serviço com equipamentos e técnicas ultrapassadas, ainda operam nas cidades do Alto Solimões. Isto exibe as estruturas de uma circulação que, apesar de contar com barcos modernos como as lanchas "ajato", ainda devem sua operacionalidade aos equipamentos antigos, mas úteis para a fluidez dos serviços da navegação regional nestes espaços opacos.

\section{OS FLUXOS DAS LANCHAS “AJATO” NO AMAZONAS}

Para uma melhor leitura de uma modernização pretérita a partir das lanchas "ajato" no rio Solimões, propõe-se uma categorização a partir da origem das viagens das lanchas. Por conseguinte, referencia-se Silveira (1999, p. 416) quando discute que:

Reconheceríamos dois subtipos de geografia luminosa. De um lado, a luminosidade primária, na qual, embora as configurações territoriais apareçam como empecilhos à nova modernidade, são acolhidas as instâncias de controle no comando do território [...]. E, de outro lado, mencionamos a luminosidade secundária, de segundo grau, dependente. É o exemplo dos pontos da verticalidade que encarnam uma luminosidade submetida a difração. Dadas as possibilidades técnicas e organizacionais do período, as regiões tornam-se teleorganizadas, comandadas desde pontos longínquos. Redes hegemônicas e domésticas, por vezes convergentes, por vezes opostas, produzem uma nova territorialidade. Uma circulação veloz e um controle remoto são, talvez, as características fundamentais de um espaço movediço e inconstante da ordem global. (SILVEIRA, 1999, p. 416/417).

Baseado na reflexão da geografia luminosa de Silveira (1999), classificamse os fluxos das lanchas "ajato" para discussão de uma modernização seletiva e 
pretérita que pode ser lida na medida em que as técnicas e infraestruturas são modificadas quanto mais se afastam do ponto primordial de irradiação dos fluxos.

Sendo assim, os fluxos primários, são definidos pelas lanchas que partem de espaços luminosos. No caso do Amazonas, referem-se àqueles situados em sua capital Manaus, onde os elementos do meio técnico-científico-informacional são mais densos e atuantes na dinâmica do espaço.

Os fluxos secundários partem das cidades intermediárias do rio Solimões para outros municípios no interior do estado. Considera-se que as hinterlândias de Tefé e Tabatinga possuem fluxos secundários significativos que corroboram para uma produtividade espacial vinculada a estes lugares distantes de espaços luminosos. Isto se justifica por Tefé ser o maior centro urbano e possuir a maior região de influência no estado do Amazonas depois da capital Manaus; e por Tabatinga contar com alta frequência de fluxos ao seu entorno com a tríplice fronteira onde os territórios do Peru, Colômbia e Brasil se encontram.

E finalmente, os fluxos terciários, que representam aqueles irradiados pelas cidades intermediárias ou regionais para as centenas de comunidades ribeirinhas localizadas nos rios, furos, paranás e igarapés da Bacia do rio Solimões. Estes fluxos terciários são movidos pelos serviços oferecidos por lanchas menores via fretamentos por firmas, instituições e pessoas para fins diversos (Figura 3).

Figura 3 - As lanchas dos Fluxos Primários à esquerda; dos Fluxos Secundários no meio; e dos Fluxos Terciários à direita

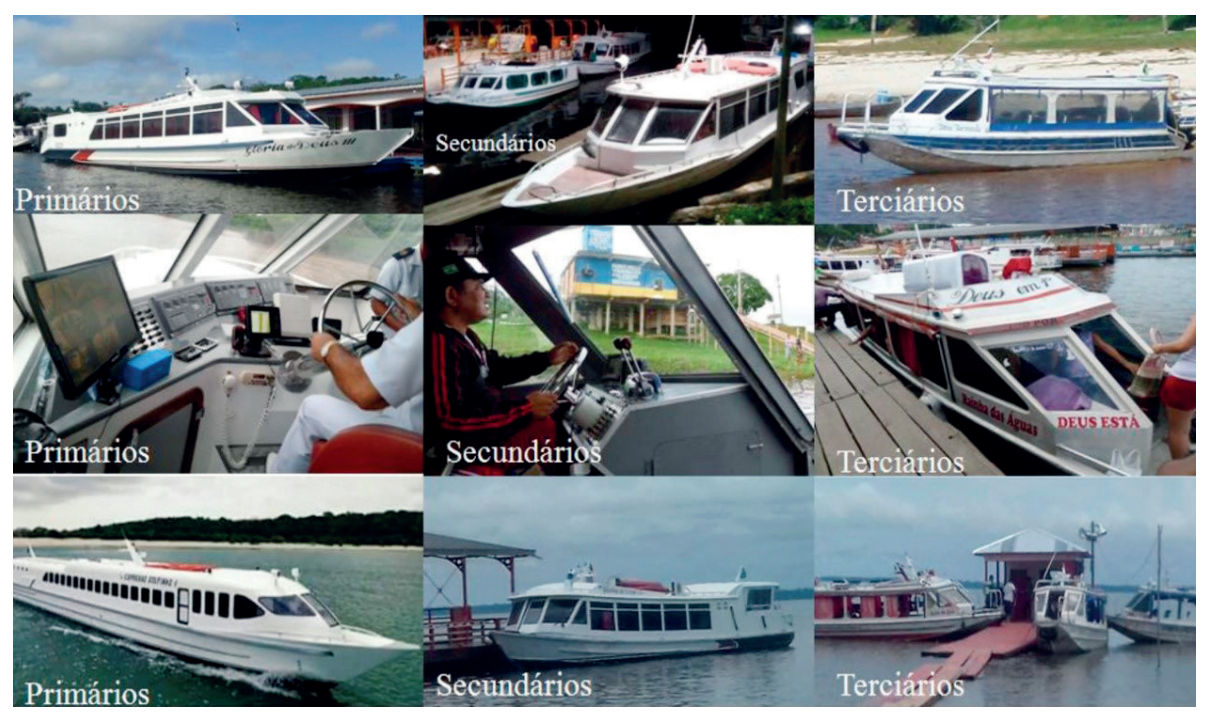

Fonte: Acervo do autor, 2017 
Quanto mais distantes dos fluxos primários, ou seja, da rota principal no Solimões entre Manaus-Tabatinga, as funcionalidades dos fluxos secundários e terciários se apresentam maiores. As lanchas "ajato" tornam-se objetos geográficos representantes da rapidez e da aceleração com a diminuição do espaço em função da aceleração do tempo (Quadro 2).

Quadro 2 - Os equipamentos das lanchas de acordo com o tipo dos fluxos

\begin{tabular}{|c|c|c|c|c|c|c|}
\hline \multirow{2}{*}{ LANCHAS } & \multicolumn{5}{|c|}{ EQUIPAMENTOS } \\
\cline { 2 - 7 } & GPS & $\begin{array}{c}\text { Ecoba- } \\
\text { tímetro }\end{array}$ & $\begin{array}{c}\text { Ar condi- } \\
\text { cionado }\end{array}$ & $\begin{array}{c}\text { Rádio (co- } \\
\text { municações) }\end{array}$ & $\begin{array}{c}\text { TV } \\
\text { (Filmes) }\end{array}$ & Motores \\
\hline $\begin{array}{c}\text { Fluxos } \\
\text { Primários }\end{array}$ & Sim & $\operatorname{Sim}$ & $\operatorname{Sim}$ & $\operatorname{Sim}$ & $\operatorname{Sim}$ & $\begin{array}{c}\text { Alta Potência } \\
\text { (Acima de } \\
500 \text { HP; possuem } \\
\text { de 1 a 3 motores) }\end{array}$ \\
\hline $\begin{array}{c}\text { Fluxos } \\
\text { Secundários }\end{array}$ & Não & $\operatorname{Sim}$ & $\operatorname{Sim}$ & Não & Não & $\begin{array}{c}\text { Alta/Média } \\
\text { Potência } \\
\text { (possuem 1 } \\
\text { motor com até } \\
400 \text { HP) }\end{array}$ \\
\hline $\begin{array}{c}\text { Fluxos } \\
\text { Terciários }\end{array}$ & Não & Não & Não & Não & Não & $\begin{array}{c}\text { Baixa /Média } \\
\text { Potência } \\
\text { (possuem 1 } \\
\text { motor com até } \\
175 \text { HP) }\end{array}$ \\
\hline
\end{tabular}

Fonte: Elaboração própria, 2017

As diferenças entre as lanchas atuantes em cada fluxo são relevantes, oferecendo técnicas e equipamentos modernos que vão se ofuscando e se alterando na medida em que se afastam de centros luminosos.

\subsection{OS FLUXOS PRIMÁRIOS DAS LANCHAS “AJATO”}

As embarcações pertinentes aos fluxos primários são as maiores e mais bem equipadas da frota das lanchas "ajato". Representam uma modernidade que possui as técnicas e estruturas contemporâneas como aliadas para vencer a resistência do espaço letárgico e opaco do Solimões. Contam com terminais próprios em Manaus e Tefé (Figura 4). 
Figura 4 - Os Terminais das Lanchas "Ajato”, de Manaus à esquerda e de Tefé à direita

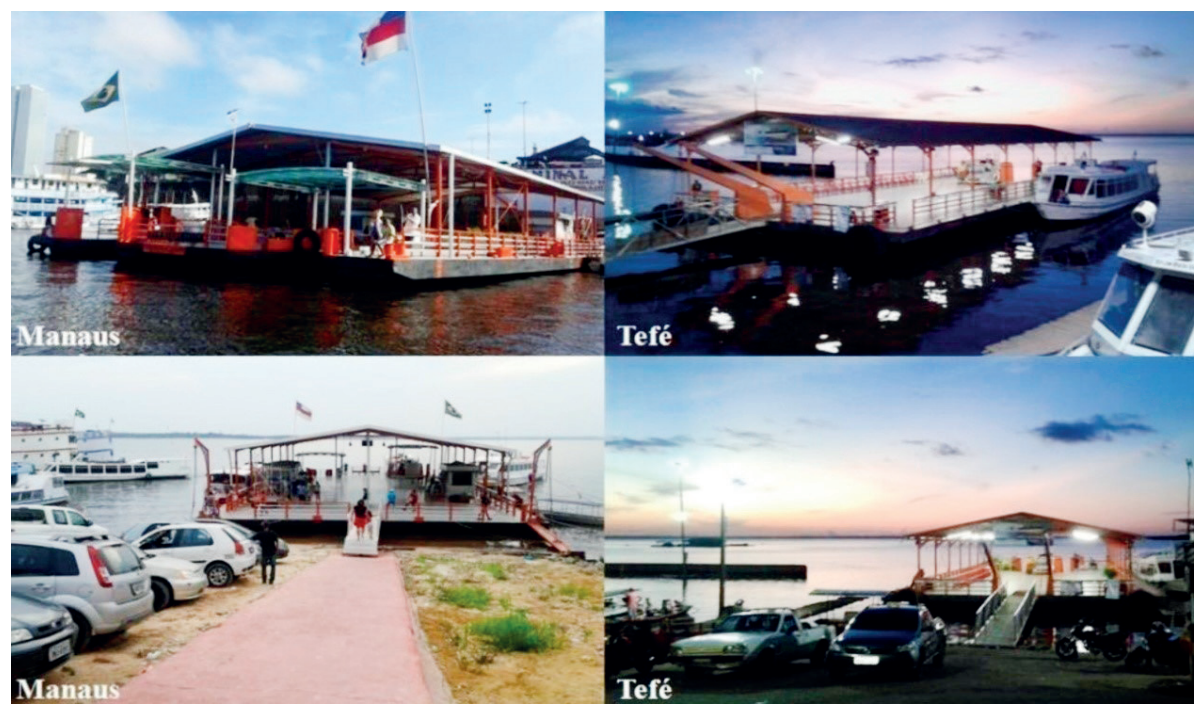

Fonte: Acervo do Autor, 2016

De Manaus, as lanchas “ajato” realizam as viagens mais custosas subindo o rio até Tabatinga, atendendo a 18 municípios que possuem demanda neste percurso. A capital amazonense, detentora de uma circulação fluvial incomparável na região e de uma notável divisão territorial do trabalho em que atuam elementos do meio geográfico contemporâneo, apresenta infraestruturas e densidade técnica para este comando primário que sedia as empresas/armadores e a origem dos fluxos primordiais para a realização da gestão desta rede de transportes no rio Solimões.

A lancha Crystal I é a maior embarcação representante dos fluxos primários. Com capacidade para 130 passageiros, atende rigidamente aos regulamentos e normas da navegação e de segurança naval. Percorre os $1.573 \mathrm{~km}$ navegáveis entre Manaus e Tabatinga em 36 horas. Leva enfermeiros, comandantes habilitados e tripulação uniformizada aos serviços rotineiros em todos os turnos, pois a viagem é contínua. Sua tripulação atende aos passageiros constituídos por profissionais liberais, comerciantes e funcionários públicos principalmente.

Existem 7 lanchas "ajato" com rota compreendendo o rio Solimões. A Crystal I, Glória de Deus III, Madame Crys e Cidade de Manaquiri realizam a rota Manaus-Tabatinga. As lanchas Puma, Ajato 2000 e Belíssima atendem até a rota Manaus-Tefé. A lancha Ajato Belíssima prossegue de Tefé até Carauari no 
rio Juruá. Estas lanchas “ajato” operacionalizam os fluxos primários, pois zarpam de Manaus, com fluxo de 10 viagens semanais. Transportam entre 65 (Lancha Puma) e 130 passageiros (Lancha Crystal I), com passagens que variam de acordo com a distância para o destino, entre 170 a 570 reais.

Apesar do rio Solimões ser considerado uma hidrovia, não possui balizamento e nem sinalização. As lanchas devem operar respeitando o regime de cheia do rio, onde redemoinhos ou "rebojos" devem ser evitados, assim como os bancos de areia e praias submersas mais comuns no período da seca dos rios, e, igualmente, materiais suspensos na água, que podem quebrar as hélices, precisando ser desviados mesmo nas viagens noturnas. Em algumas cidades sua rápida escala é realizada na madrugada com atracadouros de difícil acesso, como em Fonte Boa e Jutaí, o que dificulta, mas não diminui, o fluxo de passageiros.

Nas cidades do Solimões, as passagens das lanchas são vendidas em guichês da própria empresa "Ajato", como em Tefé e Coari, ou são disponibilizadas por representantes de vendas que ganham $5 \%$ do valor das passagens. As cidades do interior do Amazonas são pouco providas com "canais eletrônicos financeiros" (CONTEL, 2006), tais como ponto de recebimento de cartão de crédito e débito, caixas eletrônicos e redes de internet banking que facilitam a dispersão dos serviços bancários pelo território. Ou seja, só há vendas de passagens com dinheiro; compras virtuais e eletrônicas não são viabilizadas. Isto exibe uma configuração territorial que não permite o uso de técnicas contemporâneas de vendas de passagens no Solimões. Apesar de ocorrer uma modernização dos objetos de transporte, não há o acompanhamento suficiente de estruturas técnicas que deveriam supri-los.

Na última cidade da rota no Solimões, Tabatinga, na fronteira com a Colômbia e o Peru, as lanchas “ajato” ancoram no chamado PORTOBRÁS ou "Porto do Voyager" pertencente à empresa dos Navios-motores "Voyager". A ancoragem é complexa, pois o espaço para os barcos é pequeno nesta Instalação Rudimentar (ANTAQ, 2013), que opera quando da inatividade do Terminal Hidroviário de Tabatinga, uma Instalação Portuária Pública de Pequeno Porte ou IP4, presentes em 10 dos 18 municípios do rio Solimões. Estes portos do Solimões estão sob a gestão da Administração Hidroviária da Amazônia Ocidental (AHIMOC), que providencia as demandas acolhidas pelo Departamento Nacional de Infraestruturas de Transportes (DNIT). Nos municípios que possuem os portos IP4 há licitações para que empresas terceirizem a administração, os serviços de vigilância e a manutenção da operacionalidade. Ressalta-se que a 
empresa "ADC Ventureli", de Manaus, foi a última administradora deste terminal.

Não há em Tabatinga a mesma facilidade de atracação para as lanchas "ajato" como ocorre em Tefé, que possui um terminal para esse tipo de embarcação. Apesar de Tabatinga possuir um terminal hidroviário com infraestrutura superior ao de Tefé, cidade que é o maior centro urbano do Solimões (QUEIROZ, 2015), está suscetível às interrupções das atividades e inoperância de seu Terminal Hidroviário devido às licitações obstruídas por atrasos burocráticos e administrativos.

\subsection{OS FLUXOS SECUNDÁRIOS DAS LANCHAS AJATO}

Existem outras lanchas com estruturas diferenciadas no Solimões realizando os mesmos trechos entre as cidades do interior do estado, partindo principalmente de Tefé com preços e estruturas menores.

Essas lanchas “ajato”, que atendem aos fluxos secundários, não são tão modernas e nem possuem o mesmo padrão de serviços dos oferecidos pelas lanchas dos fluxos primários, porém efetuam um papel relevante para a circulação de passageiros ofertando velocidade e rapidez em relação aos outros segmentos do transporte fluvial regional com os quais concorrem. David e Nogueira (2010) afirmam que o aumento da procura desse segmento da navegação fluvial amazônica tem sido uma constante, havendo, assim, uma mudança no padrão de navegação da Amazônia, pois alguns deslocamentos, que em embarcações tradicionais eram realizados em dias, são percorridas em horas pelas lanchas dos fluxos secundários.

Nesta perspectiva, reflete-se sobre as palavras de Monié (2011, p.160) quando:

[...] para garantir a continuidade dos fluxos e articular de forma eficiente todas as escalas geográficas os integradores logísticos procuram eliminar as hierarquizações espaciais desenvolvendo estratégias que heterogeneizam o mesmo espaço na medida em que a explosão de fluxos pequenos requer mecanismos de centralização destes fluxos para criar ordem e economia de escalas (MONIÉ, 2011, p.160).

Sob esta percepção, observou-se que as cidades de Tefé e Tabatinga efetuam um papel de entrepostos fluviais referenciais que tendem a centralizar os fluxos de pequenas e grandes distâncias, assim como de alta frequência, criando uma consequente ordem e economia das escalas. A fluidez territorial é viabilizada 
via a especificidade técnica e normativa do território (ARROYO, 2015, p.44). Nesse subespaço essa fluidez é maior no rio Solimões, tendo naquelas duas cidades importantes nós de rede (Figura 5).

Figura 5 - O espaço de atuação dos fluxos primários das lanchas "ajato", acima, e dos fluxos secundários, abaixo.

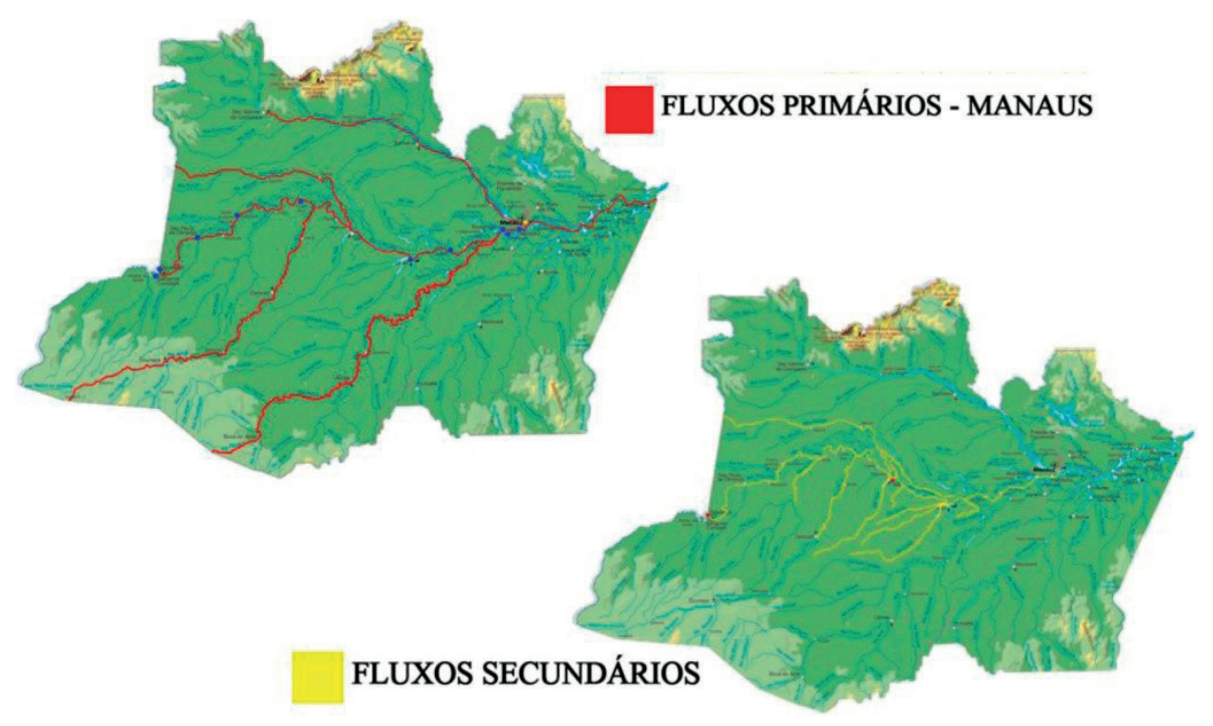

Fonte: Elaboração própria (2017) com base de dados do IBGE (2013)

Como agentes de integração territorial, pois levam repercussões econômicas de um lugar ao outro via as pessoas que transportam, essas lanchas usufruem das estruturas locais e, ao mesmo tempo, exigem sua funcionalidade. Isto ocorre pelas conexões direcionadas de pequenas cidades locais para cidades intermediárias ou regionais (Tefé e Tabatinga), e destas para a metrópole manauara, possibilitando uma reflexão sobre a hierarquia desses fluxos a partir de sua origem, ou seja, a origem das viagens das lanchas propicia identificar os pontos onde há uma modernização seletiva. No caso, Tefé, Tabatinga e a grande Manaus se configuram como centros de alta fluidez. Desta forma, estes centros propiciam benefícios para a circulação e para a dinâmica de sua hinterlândia ao irradiar "fluxos virtuosos para a integração" (QUEIROZ, 2015).

Em Tefé, o maior centro urbano do Solimões, os fluxos secundários partem do Terminal do "Ajato" local, único no Solimões e fora de Manaus. Estes fluxos secundários são constituídos por rotas importantes para a integração 
e comunicação regional, pois acessam logradouros como casas flutuantes e comunidades que estão à beira dos rios Solimões, Uarini, Tefé, Japurá e Juruá. Levam pequenas encomendas, cartas e recados para os que não possuem Correios para se comunicar, parando em lugares que outras embarcações do transporte regional teriam dificuldade, no entanto, sem atrasar a viagem.

As lanchas que operam nos fluxos secundários tefeenses são: “Glória de Deus II", que parte de Tefé para os municípios de Alvarães no rio Solimões, assim como para os municípios de Japurá e Maraã, situados no rio Japurá; a "Lancha Oliveira II", que parte de Tefé para a cidade de Alvarães e a cidade de Juruá no rio Juruá; e com destino ao município de Uarini zarpam de Tefé as Lanchas "Lima de Abreu VI", "Lima de Abreu III", "Expresso Hélio Mota", "Lancha Tayson" e "Expresso Iara" que também atendem Alvarães.

Estas lanchas com rota para Uarini efetuam uma frequência de 21 viagens semanais e possuem capacidade de 27 passageiros; as lanchas que se dirigem para Japurá, Maraã e Juruá têm capacidade de 65 pessoas, frequência de 2 viagens semanais e com passagens no valor de 180 reais. Todas essas respectivas lanchas atendem à cidade de Alvarães. Ressalta-se que Tefé, Uarini e Alvarães constituem a Microrregião de Tefé.

$\mathrm{Na}$ região do Solimões os objetos técnicos que compõem os fixos especializados do transporte fluvial são limitados. Por conseguinte, a empresa "Ajato" instalou o Terminal do "Ajato" de Tefé, que é a capital regional do Solimões, cidade com posição estratégica no meio da extensão do grande rio, no centro do Amazonas e na foz dos rios Japurá e Tefé (QUEIROZ, 2015). Este terminal possui um papel e uma expressividade diferenciada, pois não serve apenas aos objetivos das lanchas “ajato", mas também de outras embarcações que utilizam suas estruturas para atracar. Assim, um objeto técnico como esse Terminal do "Ajato" em Tefé aprimora os fluxos e os fixos regionais frente a escassez de portos e terminais públicos e privados de embarque e desembarque de passageiros e cargas. Ressalta-se que Tefé não possui um porto IP4, apenas flutuantes de madeira e uma balsa-porto que efetuam o papel de um entreposto fluvial para toda a circulação regional.

Por conseguinte, o Terminal do "Ajato" em Tefé representa uma modernização dos fixos especializados ao transporte fluvial via a operação das lanchas "ajato", pois disponibiliza estruturas e equipamentos que os demais terminais locais não possuem, tais como: i) estruturas de aço; ii) gerador de 
energia; iii) escada para embarque e desembarque de idosos e crianças; iv) guichê de vendas de passagens; v) acesso facilitado no período de seca (praia) e de cheia dos rios; vi) técnicas e organização diferenciadas (lanche, cadeiras, carregadores, taxistas etc.). No entanto, este Terminal do "Ajato" não deixa de ser configurado como uma Instalação Rudimentar pela Agência Nacional de Transportes Aquaviários (ANTAQ).

\subsection{OS FLUXOS TERCIÁRIOS DAS LANCHAS AJATO}

Os fluxos terciários compõem a categoria dos fluxos das lanchas "ajato" constituídos por lanchas que efetuam fluxos fundamentais para a integração territorial do subespaço em consideração. Estes fluxos terciários se originam principalmente em Tefé e Tabatinga, mas também em outras cidades do rio Solimões, porém com menor frequência e organização, e se dirigem para as comunidades e localidades ribeirinhas dispersas nos afluentes, paranás, furos e igarapés do "rio mar".

Apesar dessas lanchas dos fluxos terciários estarem sob os condicionantes de uma solidariedade e um cotidiano tradicional, ou seja, das horizontalidades, executam modelos de operacionalização de espaços luminosos. Contudo, oferecem serviços de navegação que funcionam a partir de novas organizações sociais e de um contrato peculiar. São de porte menor e de maior desobediência à racionalidade hegemônica. É nesse momento que a modernização pretérita se realiza de maneira mais intensa, pois se figura como uma modernização adaptada a funcionar com o escasso, com o barato, com o disponível e com o limitado.

Essas respectivas lanchas não possuem equipamentos modernos, apenas o design "manauara" que se assemelha ao das lanchas que compõem os fluxos primários. Entretanto, são lanchas que buscam melhorar o serviço das pequenas embarcações tradicionais, as catraias, mais lentas e sem cobertura contra o sol e chuva. Os motores das lanchas do fluxo terciário são até 20 vezes mais potentes do que uma catraia tradicional, promovendo rapidez e o acesso à aceleração para a clientela cabocla a um custo semelhante ao das catraias. Realiza-se uma modernização com objetos pretéritos, pois, mesmo que existam objetos funcionalmente mais ágeis a partir dessas lanchas, são tecnologias antigas para o mundo contemporâneo. 
Os fluxos terciários de Tefé são relevantes quando analisadas as atividades da Associação dos Catraieiros de Tefé, composta por 24 associados que utilizam três flutuantes como atracadouros. A maior frequência de fluxos terciários no município é para a Vila de Nogueira, no rio Tefé, acesso para o município de Alvarães, no rio Solimões. A frequência desse fluxo equivale a 185 viagens semanais efetuadas pelas lanchas.

Muitas catraias tradicionais e voadeiras continuam operando com destino para as 107 comunidades ribeirinhas localizadas no rio Tefé. Porém, a fragilidade das pequenas embarcações tradicionais provoca acidentes e mortes, o que motivou os usuários deste tipo de transportes (estudantes, professores, comerciantes e agricultores, principalmente) a utilizarem cada vez mais as lanchas dos fluxos terciários do transporte fluvial.

Em Tabatinga, os fluxos terciários partem do chamado Porto das Catraias onde se localizam os flutuantes que sediam as atividades da Associação dos Taxistas Fluviais de Tabatinga, no Flutuante Princesa do Alto Solimões; e da Associação dos Canoeiros Cargueiros de Tabatinga (ACANTURTAB) no Flutuante "Tres Fronteras", onde atuam profissionais peruanos de Santa Rosa, comunidade peruana localizada do lado oposto a Tabatinga. Essas associações são dois entes que operacionalizam os fluxos intermunicipais entre Tabatinga e Santa Rosa (Peru), assim como Tabatinga e as cidades de São Paulo de Olivença, Benjamin Constant e Santo Antônio do Iça. Cada uma dessas cidades possui sua associação que irradia viagens pertinentes aos fluxos terciários.

Entre Tabatinga e Santa Rosa, o fluxo diário ultrapassa 100 viagens com os 20 associados da ACANTURTAB. Taxistas fluviais da Associação dos Taxistas Fluviais de Santa Rosa afirmam que, somando as três associações de profissionais associados na tríplice fronteira, ou seja, as duas respectivas associações brasileiras e a peruana, ultrapassam 100 sócios. De acordo com o taxista fluvial José Valeran, os armadores colombianos possuem a licença para entrar no Brasil, porém os taxistas brasileiros afirmam que não são bem-vindos nos setores fluviais colombianos por não terem acesso a essa licença, efetuando, quando necessário, viagens clandestinas pertinentes aos fluxos terciários.

O fluxo entre Tabatinga e São Paulo de Olivença compõe-se em torno de 7 viagens diárias (4 horas de duração), entre Tabatinga e Benjamin Constant somam 11 viagens diárias (25 minutos de duração). As viagens de Tabatinga para a cidade de Santo Antônio do Iça possuem poucos fluxos semanais, pois 
a Associação dos Taxistas da própria cidade de Santo Antônio do Iça efetua algumas viagens. Estas viagens não possuem horários definidos, os armadores disponibilizam e operacionalizam seus serviços de transporte fluvial via a contratação ou fretamentos das viagens sem planejamento prévio e, por isso, não possuem rotas e horários pré-estabelecidos.

As pequenas lanchas dos fluxos terciários de Tabatinga realizam rotas intermunicipais na região do Alto Solimões, rotas que são realizadas por lanchas maiores, dos fluxos secundários no Médio Solimões. Isto permite uma "intercambialidade de objetos" que se realiza pela complexidade entre os níveis e estruturas das lanchas e os fluxos e serviços a serem atendidos por estas. Ou seja, as lanchas dos fluxos terciários em Tabatinga, com estruturas e técnicas menores e pretéritas, realizam as viagens intermunicipais que em Tefé são efetuadas pelas as lanchas dos fluxos secundários (Figura 6). Porém, em Tefé essas viagens intermunicipais possuem rotas definidas e são operacionalizadas por lanchas com estruturas maiores supridas com técnicas e equipamentos mais modernos, entretanto inferiores às lanchas “ajato” dos fluxos primários advindas de Manaus.

Figura 6 - Principais lanchas dos fluxos terciários de Tabatinga, Santa Rosa (Peru), à esquerda; e Tefé e Coari, à direita.

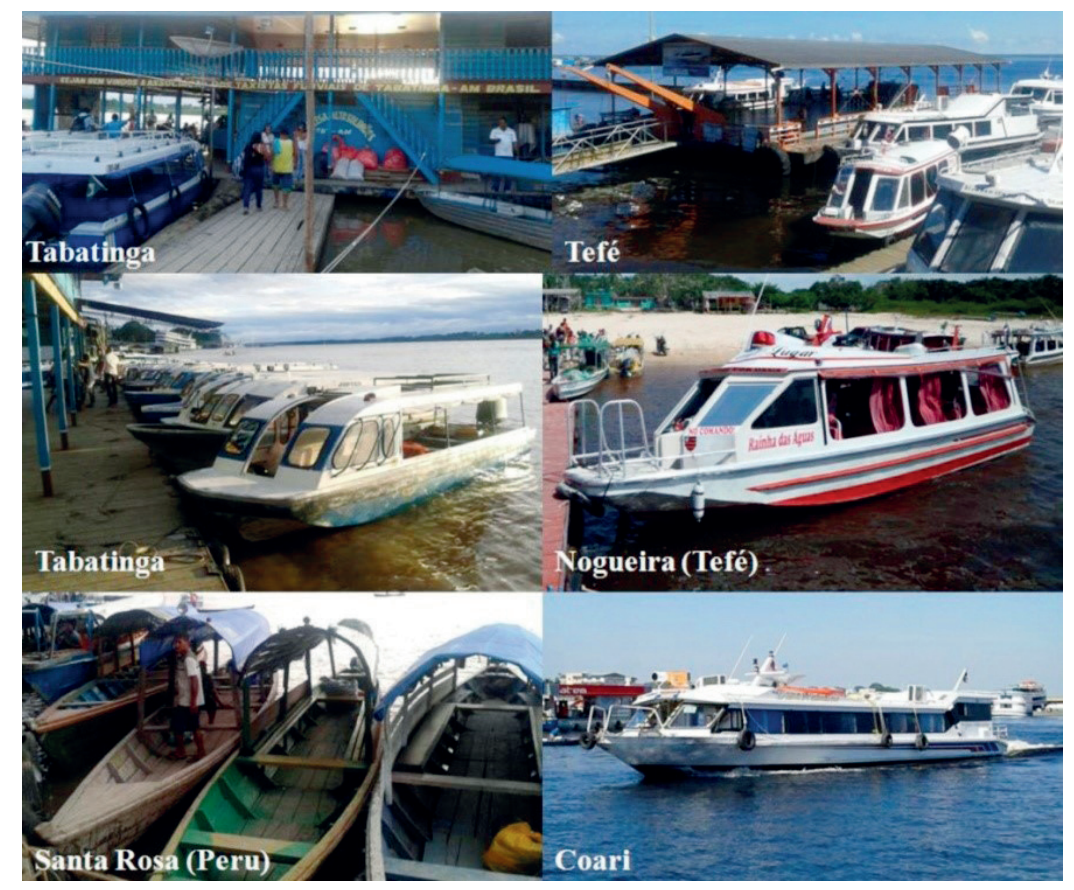

Fonte: Acervo do autor, 2017 
Evidencia-se que isso ocorre em razão de que quanto mais distante de Manaus, centro dispersor dos fluxos primários, menor a possibilidade de viabilização de uma plena operacionalização de equipamentos modernos e técnicas contemporâneas. Isso porque Manaus conta com maior densidade de técnicas relacionadas à modernidade, e, concomitantemente, à gestão institucional, à assistência técnica, à manutenção das lanchas; assim como é a cidade onde os elementos que compõem o meio técnico-científicoinformacional são mais presentes

Somam-se a essa incapacidade de territórios distantes, como Tabatinga, em gerir objetos modernos longe do centro difusor de fluxos (Manaus), as condições socioeconômicas da população, detentora de um baixo poder aquisitivo; tanto dos passageiros quanto da iniciativa privada local, ou seja, a demanda, as iniciativas e os investimentos são limitados.

Logo, essas lanchas se inserem em um processo de modernização pretérita, cujos objetos e equipamentos velhos ainda são úteis para disseminar mobilidade e rapidez, atraindo passageiros e fluindo a circulação que corrobora para uma integração territorial desses espaços letárgicos.

Ressalta-se que, apesar de prover uma circulação fluvial significativa, o município de Coari no Médio Solimões, não possui lanchas que operam rotas pré-estabelecidas para os municípios vizinhos e por isso não gera fluxos secundários para outras cidades, não produzindo desta forma benefícios para a integração territorial. Nesta cidade, os fluxos terciários se baseiam no transporte de funcionários por empresas/armadores terceirizados da Petrobrás levando trabalhadores e funcionários para a Província Petrolífera do Urucu.

\section{CONSIDERAÇÕES FINAIS}

Conclui-se que, apesar de ocorrer uma modernização dos objetos do transporte fluvial representados pelas lanchas "ajato" no rio Solimões, a estrutura técnica do território ainda possui dificuldades para acompanhar esse processo. Assim, a insuficiência de terminais portuários, postos de abastecimentos e canais eletrônicos financeiros perpetua o uso de equipamentos e técnicas de divisões territoriais do trabalho pretéritas, ou seja, os fixos não acompanharam a modernização dos fluxos, promovendo uma modernização pretérita. 
Verificou-se que as lanchas “ajato" efetuam rotas distintas e diferentes tipos de lanchas estabelecem uma rede ligando a determinados nodais de embarque e desembarque de passageiros dentro da circulação inerente ao transporte fluvial no rio Solimões. Os "ventos" da globalização e da racionalidade que prezam pela aceleração e pela rapidez advindas da divisão territorial do trabalho contemporânea alcançaram a dinâmica da circulação fluvial no Solimões por intermédio da organização diferenciada dos serviços e das infraestruturas que subsidiam os fluxos e os fixos às lanchas "ajato".

A instalação e manutenção do Terminal do "Ajato" em Tefé, cidade que se configura como o centro gestor do território no Solimões, também exibem a inserção de técnicas e equipamentos modernos. Representa uma modernização dos fixos especializados ao transporte fluvial vinculado aos fluxos regionais das lanchas "ajato" que beneficia significativamente o transporte fluvial na região, pois socializam seu uso com outras embarcações em um subespaço onde estas infraestruturas são escassas; assim como contribui para intensificar a produtividade espacial deste nó de rede no Solimões.

Esta pesquisa ofereceu subsídios para compreender que a partir da classificação dos fluxos das lanchas "ajato" por intermédio de sua origem, foi possível identificar uma modernização com objetos antigos tanto dos fluxos como dos fixos especializados no transporte fluvial, uma modernização pretérita. Estas novas ações com objetos velhos tornam a circulação fluvial limitada, todavia promovem uma integração territorial importante nestes subespaços distantes dos centros econômicos e das infraestruturas modernas.

Os fluxos primários, secundários e terciários evidenciam a importância das lanchas "ajato" para o transporte fluvial no Solimões e efetuam uma modernização da frota e dos equipamentos das embarcações tradicionais. Constatou-se que corroboram para a integração territorial, pois as lanchas "ajato" dos fluxos primários são os únicos segmentos do transporte fluvial do Solimões que atendem às cidades mais importantes do grande rio, o que não é realizado pelos Navios-motores e os ferry-boats. Ademias, o papel dos fluxos secundários e terciários são significativos para o fortalecimento de uma produtividade espacial útil à circulação e, concomitantemente, à integração territorial desse subespaço à formação socioespacial brasileira. 


\section{REFERÊNCIAS}

ANTAQ. Caracterização da oferta e demanda do transporte fluvial de passageiros na região na região amazônica. Brasília: ANTAQ, 2013.

ARROYO, M.; CRUZ, R. C. A. (Orgs). Território e circulação: a dinâmica contraditória da globalização. São Paulo: Annablume, 2015.

BAUDRILLARD, J. O sistema de objetos. São Paulo: Perspectiva, 2012.

CONTEL, F. B. Território e finanças: técnicas, normas e topologias bancárias no Brasil. Tese (Doutorado em Geografia Humana) - Faculdade de Filosofia, Letras e Ciências Humanas da Universidade de São Paulo. São Paulo, 2006.

DAVID, R. C. A.; NOGUEIRA, R. J, B. O transporte fluvial expresso: um novo segmento na rede fluvial amazônica. XVI ENCONTRO NACIONAL DOS GEÓGRAFOS. Anais [...]. Porto Alegre: jul. 2010.

HARVEY, D. A produção capitalista do espaço. São Paulo: Annablume, 2005. HUERTAS, D. M. Da fachada atlântica ao âmago da hiléia: integração nacional e fluidez territorial no processo de expansão da fronteira agrícola. Dissertação (Mestrado em Geografia Humana) - Faculdade de Filosofia, Letras e Ciências Humanas da Universidade de São Paulo. São Paulo, 2007.

INSTITUTO BRASILEIRO DE GEOGRAFIA E ESTATÍSTICA (IBGE). Atlas do Censo 2010. Coordenação de Geografia. Rio de Janeiro: IBGE, 2013.

MONIÉ, F. Dinâmicas produtivas, logística e desenvolvimento territorial. In: VIDEIRA, S. L.; COSTA, P. A.; FAJARDO, S. Geografia econômica: (re) leituras contemporâneas. Rio de Janeiro: Letra Capital, 2011.

QUEIROZ, K. O. Centralidade periférica e integração relativizada - uma leitura de Tefé no Amazonas. Tese (Doutorado em Geografia Humana) Faculdade de Filosofia, Letras e Ciências Humanas da Universidade de São Paulo. São Paulo, 2015.

SANTOS, M. Por uma economia política da cidade: o caso de São Paulo. São Paulo: Editora Hucitec/Educ, 1994.

SANTOS, M. Técnica, espaço, tempo: globalização e meio técnico-científicoinformacional. 5. ed. Coleção Milton Santos. São Paulo: Editora da Universidade de São Paulo, 2008.

SILVEIRA, M. L. Um país, uma região: fim de século e modernidades na Argentina. São Paulo: FAPESP e LABOPLAN-USP, 1999.

Texto submetido à Revista em 20.09.2017

Aceito para publicação em 22.04.2019 
